\title{
Paraquat in the rabbit
}

\author{
COOLEY BUTLER II and JEROME KLEINERMAN \\ Department of Pathology Research, Saint Luke's Hospital, and the Institute of Pathology, \\ Case Western Reserve Medical School, Cleveland, Ohio 44106
}

\begin{abstract}
Butler, C. II, and Kleinerman, J. (1971). Brit. J. industr. Med., 28, 67-71. Paraquat in the rabbit. Forty rabbits received paraquat intraperitoneally in total dosages of from 2 to 100 $\mathrm{mg} / \mathrm{kg}$ and in one to five separate administrations. Nine animals which received $25 \mathrm{mg} / \mathrm{kg}$ or more died within four days of administration, and the remainder were killed at intervals of up to one month. The delayed pulmonary changes produced in man and other species by paraquat were not found in any animal, despite the fact that most animals were made ill by the chemical. Atrophy of the thymus and minimal renal tubular and focal peritoneal changes were present in animals found dead or killed soon after administration, but it was difficult to explain the cause of death.
\end{abstract}

The herbicide paraquat (1,1'-dimethyl-4,4'dipyridylium dichloride or dimethosulphate) has been noted to produce rapidly progressive, fatal interstitial inflammation and fibrosis of the lung in man following accidental ingestion (Bullivant, 1966; Almog and Tal, 1967; Campbell, 1968; Fennelly, Gallagher, and Carroll, 1968; Matthew, Logan, Woodruff, and Heard, 1968). In an extensive study of the toxicity of paraquat in various mammals, Clark, McElligott, and Hurst (1966) reported difficulty in producing the pulmonary lesion in rabbits with oral administration or cutaneous application of the chemical. These findings contrasted with the ease of production of pulmonary lesions in rats and mice by oral or intraperitoneal administration. They concluded that mortality in rabbits from paraquat was due mainly to inability or unwillingness to eat and drink, because of oesophagitis and glossitis resulting from the swallowing of water containing paraquat or from licking the sites of cutaneous application. We thought that injection of paraquat might avoid the difficulties of oral administration, and chose the intraperitoneal route because of the success of Clark et al.(1966) with this method in rodents. Our findings are the subject of this report.

\section{Materials and methods}

Forty immature male New Zealand white rabbits $(1.40$ to $2.25 \mathrm{~kg})$ were maintained on standard laboratory chow and water ad libitum. Each was clinically free of disease for at least one week before experimental use. Intraperitoneal injections of paraquat were given according to several schedules (Table), with total doses varying from 2 to $100 \mathrm{mg} / \mathrm{kg}$. Twenty animals were given a single dose, and eight received three equal doses at 48-hour intervals. It was planned for the remaining 12 animals to receive five equal doses at 48-hour intervals, but this schedule could be completed in only 9 , as 3 died during the period of injections. The appropriate volume of Dual Paraquat ${ }^{1}(240 \mathrm{mg}$ paraquat cation $/ \mathrm{ml})$ was diluted with normal saline to $2 \mathrm{ml}$ for each injection.

Thirty-one animals were killed by exsanguination after pentobarbital anaesthesia at one, two, or nine days, two weeks or one month; the remainder died within four days of the completion of injections. At least one animal in each group survived one month. One lung was fixed by intrabronchial inflation and the other by vascular perfusion with $10 \%$ neutral buffered formalin. Four- to six-micron paraffin sections of lung, ventricular myo-

${ }^{1}$ Kindly supplied by the Chevron Chemical Co., Ortho Div., San Francisco, California 
TABLE

Schedule for Administration of Paraquat to ANimals AND the OUTCOME

\begin{tabular}{|c|c|c|c|c|}
\hline Group & $\begin{array}{c}\text { No. of } \\
\text { animals }\end{array}$ & $\begin{array}{l}\text { Total } \\
\text { dose } \\
(\mathrm{mg})\end{array}$ & $\begin{array}{c}\text { No. of } \\
\text { injections }\end{array}$ & Fate of animals \\
\hline $\mathbf{A}$ & 3 & 2 & 1 & $\begin{array}{l}1-\mathrm{K} \text { at } 2 \text { days } \\
1-\mathrm{K} \text { at } 9 \text { days } \\
1-\mathrm{K} \text { at } 1 \text { month }\end{array}$ \\
\hline B & 3 & 10 & 1 & $\begin{array}{l}1-K \text { at } 2 \text { days } \\
1-K \text { at } 9 \text { days } \\
1-K\end{array}$ \\
\hline C & 3 & 25 & 1 & $\begin{array}{l}1-\mathrm{D} \text { at } 1 \text { day } \\
1-\mathrm{K} \text { at } 9 \text { days } \\
1-\mathrm{K} \text { at } 1 \text { month }\end{array}$ \\
\hline D & 4 & 30 & 1 & $\begin{array}{l}1-K \text { at } 1 \text { day } \\
1-D \text { at } 3 \text { days } \\
1-K \text { at } 9 \text { days } \\
1-K \text { at } 1 \text { month }\end{array}$ \\
\hline $\mathrm{E}$ & 4 & 30 & 3 & $\begin{array}{l}1-K \text { at } 1 \text { day } \\
1-K \text { at } 9 \text { days } \\
2-K \text { at } 1 \text { month }\end{array}$ \\
\hline $\mathbf{F}$ & 3 & 45 & 1 & $\begin{array}{l}1-D \text { at } 1 \text { day } \\
1-D \text { at } 4 \text { days } \\
1-\mathrm{K} \text { at } 1 \text { month }\end{array}$ \\
\hline G & 4 & 50 & 1 & $\begin{array}{l}1-\mathrm{D} \text { at } 1 \text { day } \\
1-\mathrm{K} \text { at } 9 \text { days } \\
2-\mathrm{K} \text { at } 1 \text { month }\end{array}$ \\
\hline $\mathbf{H}$ & 4 & 50 & 3 & $\begin{array}{l}1-\mathrm{K} \text { at } 1 \text { day } \\
1-\mathrm{K} \text { at } 9 \text { days } \\
2-\mathrm{K} \text { at } 1 \text { month }\end{array}$ \\
\hline I & 6 & 50 & 5 & $\begin{array}{l}1-K \text { at } 2 \text { days } \\
1-K \text { at } 2 \text { weeks } \\
4-K \text { at } 1 \text { month }\end{array}$ \\
\hline $\mathbf{J}$ & 6 & 100 & 5 & $\begin{array}{l}\text { 1-D at } 1 \text { day } \\
2-\mathrm{K} \text { at } 1 \text { month } \\
3 \text {-incomplete }\end{array}$ \\
\hline
\end{tabular}

$\mathrm{K}=$ killed $; \mathrm{D}=$ found dead; time is after completion of last injection.

${ }^{1}$ Found dead after receiving $60 \mathrm{mg} / \mathrm{kg}$ ( 2 animals) or $80 \mathrm{mg} / \mathrm{kg}$ (1 animal).

cardium, liver, spleen, pancreas and kidney from all animals were stained with haematoxylin and eosin and examined by light microscopy; sections of testis, thymus, thyroid, adrenal gland and mesenteric and mediastinal lymph nodes were examined from most animals.

Four control animals in the same weight range were given single 2-ml intraperitoneal injections of saline and killed 1, 2, 9 and 30 days afterwards. Tissues from these animals were prepared as above.

\section{Results}

Considerable toxic systemic effects with indifference to food and water were noted in most animals receiving more than $10 \mathrm{mg}$ total dose. These effects usually lasted four or five days after administration was completed, and were often accompanied by transient diarrhoea and loss of up to $15 \%$ of body weight. This lack of food intake and weight loss were most marked in animals which were found dead, all of which showed loss of body fat and appeared dehydrated at necropsy. Glosso-oesophagitis was not found in this group. Animals surviving nine days or more frequently lost large patches of fur, and although any initial weight loss had usually been made good by nine days, subsequent weight gains were often much less than the average $100 \mathrm{~g}$ per week we expected in this type of rabbit. Some rabbits, however, tolerated paraquat with very little apparent systemic effect. This tolerance was not obviously dose-related.

The thorax was opened after the trachea had been occluded in a search for collapse, but none was found. The majority of lungs showed occasional small interstitial infiltrates of lymphocytes and plasma cells, accompanied by focal and minimal alveolar lining cell hyperplasia and collections of alveolar macrophages (Fig. 1), but there was no evidence of haemorrhage, destruction or fibrosis in any lung. These small infiltrates correlated poorly with the dosage employed and the time after injection of paraquat, but they were not present in control animals. In a few of the lungs, Langhans giant cells were seen in small numbers in the interstitial infiltrates, but there was no frank granuloma formation. The pulmonary vasculature was normal in all instances. Pleural adhesions were not seen; effusions of up to $5 \mathrm{ml}$ of cloudy yellow fluid were present in three animals which died shortly after receiving $45 \mathrm{mg}$ or more of paraquat.

A few changes in other organs were present. Seven animals, scattered throughout several dosage groups, had slight hepatic coccidiosis. The number affected is not unusual for our stock rabbits. There were no other hepatic lesions in any animal. Cytoplasmic vacuolation of individual convoluted renal tubules (Fig. 2) was present in all 15 animals found dead or killed within four days of the end of administration, irrespective of dose, but was found only rarely thereafter, and never in control animals. These lesions involved only a small percentage of tubules, and frank tubular necrosis was not seen. Gross and microscopic atrophy of the thymus was present in all nine animals found dead, as well as in two which were killed at 9 and 14 days after receiving total doses of 30 and $50 \mathrm{mg} / \mathrm{kg}$, respectively. These last two animals had sustained unusually severe and prolonged weight loss after dosing without the usual clear-cut clinical improvement at around five days post-injection seen in other animals. Becauseall the animals were immature, it was difficult to assess testicular injury accurately, but in at least two rabbits, receiving 10 and $100 \mathrm{mg}$ paraquat and surviving nine days and one month respectively, the testicular tubules were lined almost entirely by Sertoli cells. In 7 of the 20 animals receiving $50 \mathrm{mg}$ of paraquat or more, multinucleate giant cells (Fig. 3) were readily found 


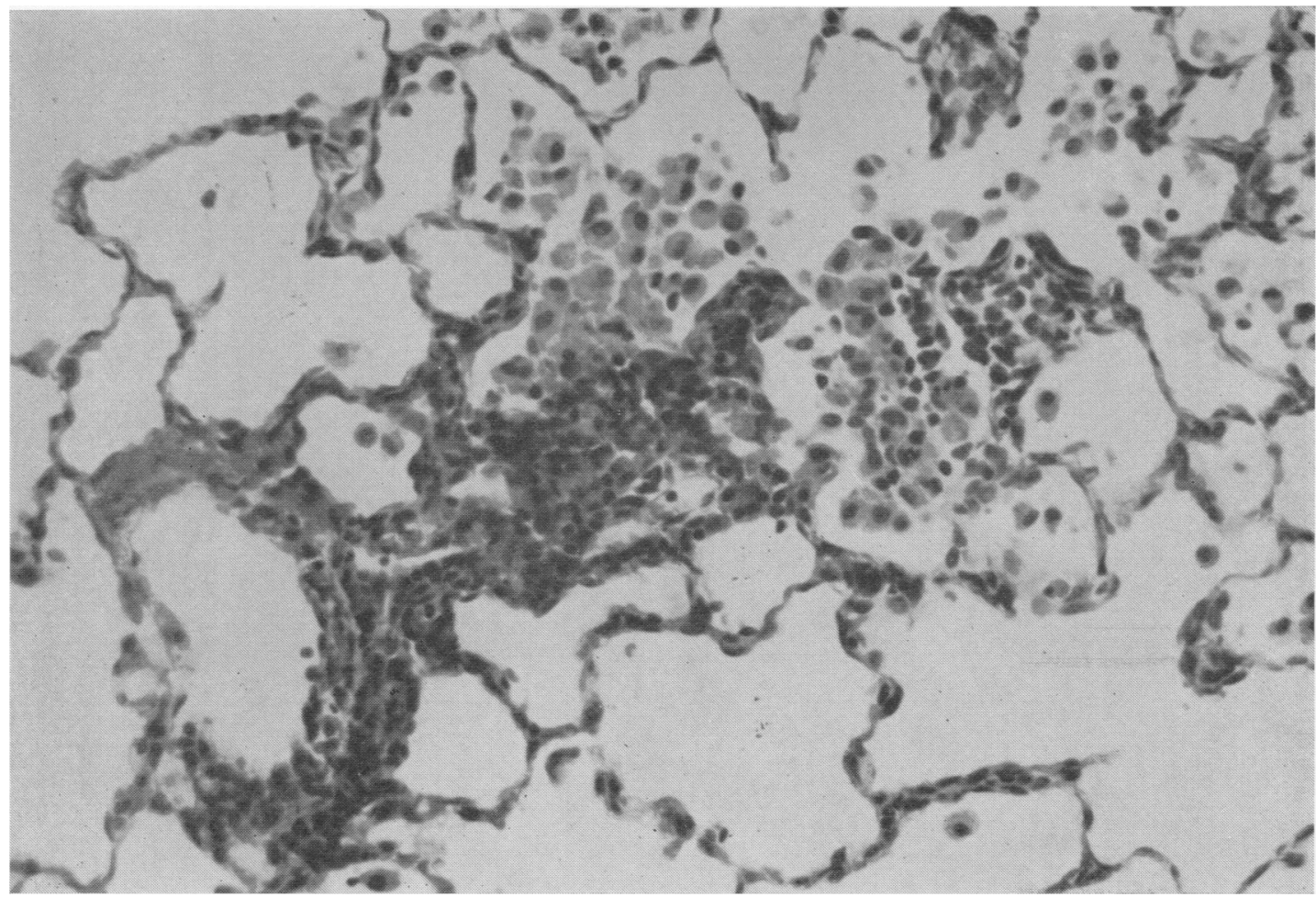

FIG. 1. Small interstitial pulmonary infiltrate, predominantly of lymphocytes and plasma cells in a rabbit which had received a total of $50 \mathrm{mg}$ of paraquat and was killed at nine days after the first dose. Note the adjacent collection of alveolar macrophages. (Haematoxylin and eosin, $\times 330$.)

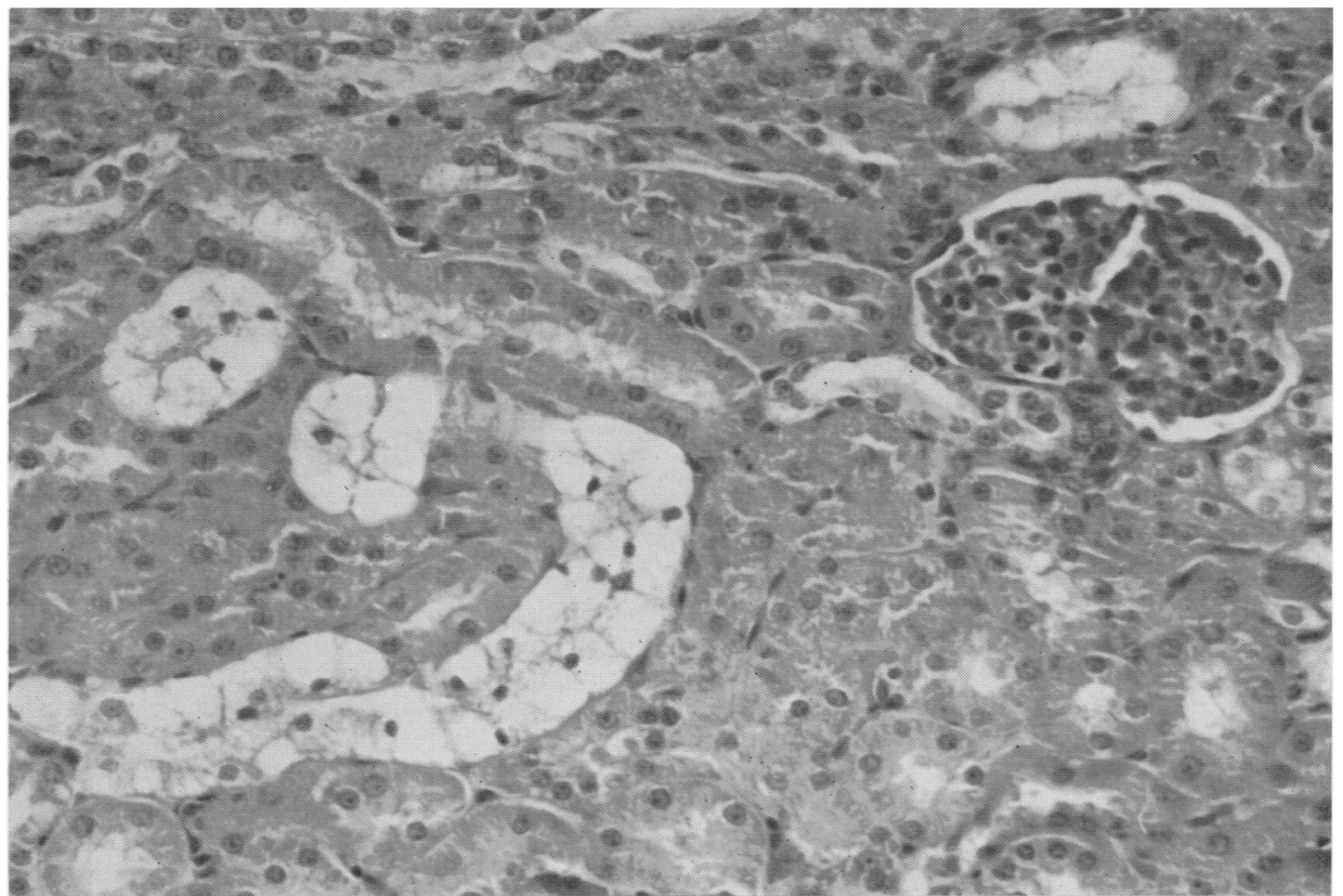

FIG. 2. Vacuolation of convoluted renal tubules in a rabbit which had received $30 \mathrm{mg}$ of paraquat and was killed at 1 day. Note that only occasional tubules are involved. (Haematoxylin and eosin, $\times 330$.) 


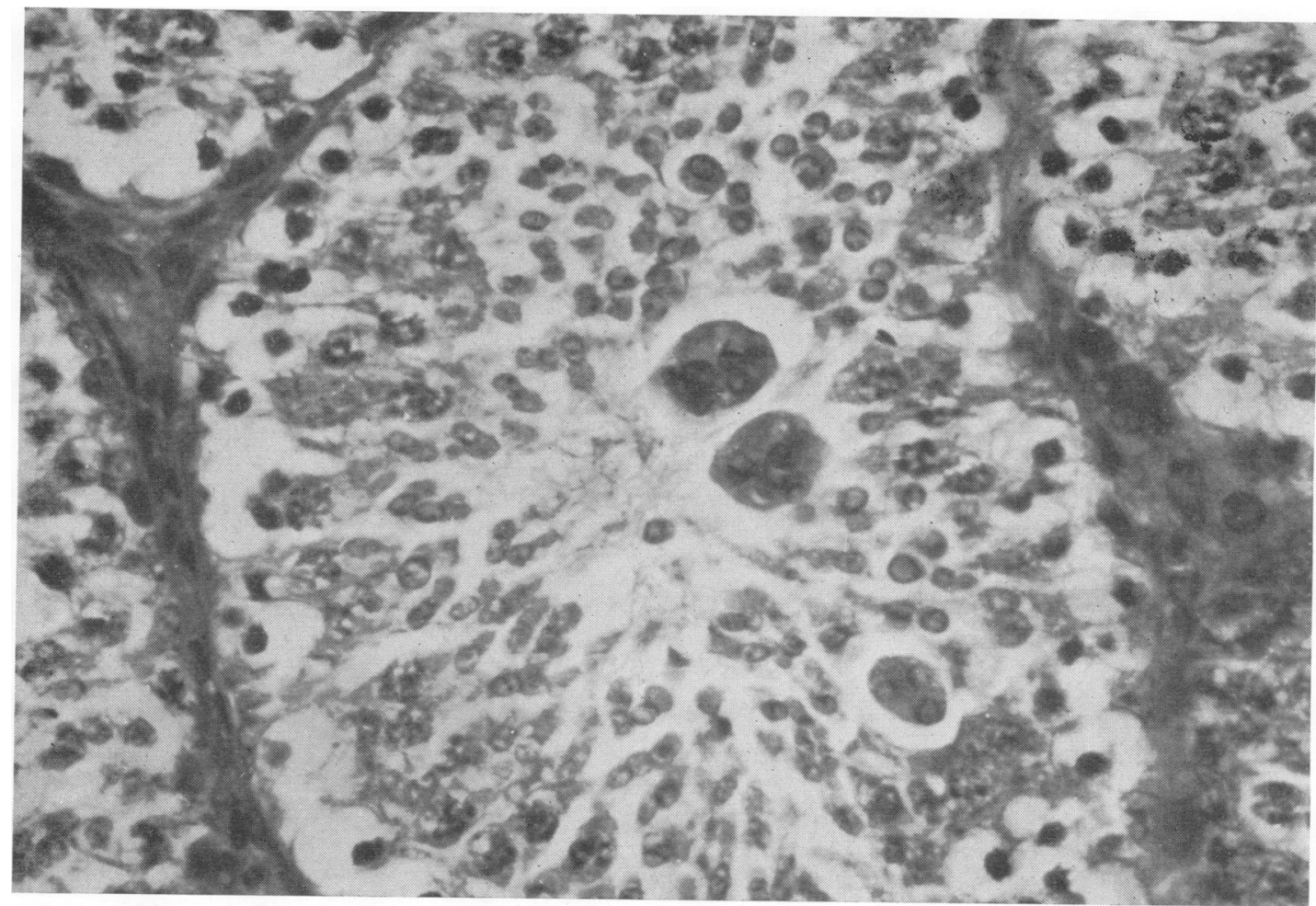

FIG. 3. Testicular tubule, containing three multinucleate giant cells in a rabbit which had received a total of $100 \mathrm{mg}$ of paraquat and was killed 1 month after the first dose. (Haematoxylin and eosin, $\times 530$.)

in the testicular tubule lumen. No thymic or testicular changes were found in the controls. Focal and minimal peritoneal inflammation was found in seven animals, all of which died or were killed within 24 hours of an injection; no peritoneal changes were seen in animals surviving longer than this. All other organs examined were grossly and microscopically normal.

\section{Discussion}

Paraquat poisoning in man is often fatal because of the development of progressive pulmonary lesions which generally manifest themselves after a delay of several days. Haemorrhagic oedema, proliferation of alveolar and bronchiolar lining cells, and interstitial inflammation and fibrosis are usually found at necropsy in man and several other mammals. Renal tubular and hepatocellular damage has also been described (Oreopoulos, Soyannwo, Sinniah, Fenton, McGeown, and Bruce, 1968). The delayed development of the lung lesions is perplexing in view of the evidence that more than $90 \%$ of the ingested paraquat ion is excreted within three or four days, both in man (Matthew et al., 1968; Kerr, Patel, Scott, and Tompsett, 1968) and in the rat (Daniel and Gage, 1966).

This study confirms the unusual resistance of the rabbit to paraquat-induced lung changes (Clark et al., 1966). Most of our animals were made ill by the injections. They usually died within four days of injection or improved clinically thereafter. There was no evidence of significant acute, delayed or progressive pulmonary disease of any kind. It does not appear that higher dosage would produce pulmonary lesions, because mortality rates would be unacceptable. The glosso-oesophagitis reported with oral administration was avoided by intraperitoneal administration, and we suspect that the poor food intake by most animals shortly after dosing was due to peritoneal inflammation, as focal peritonitis was present in about half of the rabbits found dead or killed within four days of administration.

The reason for the absence of lung changes is not known. Perhaps intraperitoneal administration, with preferential absorption into the portal circulation, prevents unaltered paraquat from entering the lung. 
However, Clark et al. (1966) produced extensive subacute pulmonary changes in rats by intraperitoneal injection, so at least in that animal there does not appear to be a significant mechanism for hepatic detoxification.

There is experimental evidence of interference with surfactant formation by paraquat (Manktelow, 1968; Fisher and Clements, 1969). Fisher and Clements reported atelectasis, altered pressurevolume characteristics and reduced surface-active material in rat lungs acutely following intravenous administration of paraquat. However, the relationship of these phenomena to the pulmonary interstitial inflammation and fibrosis which develops after a few days in rats after intraperitoneal paraquat (Clark et al., 1966) was not explored, as the observations stopped at three days. Despite a careful search for atelectasis in our animals, we found none at any time from one day after administration onward.

We are not certain of the mechanism of death in the animals found dead. There was not sufficiently severe peritonitis, renal tubular change or hepatic coccidiosis alone to account for death in any animal. In some, the dehydration resulting from failure to eat and drink, sometimes with mild diarrhoea, resulted in considerable acute weight loss and was undoubtedly an important factor. The only consistent change found in these animals was thymic atrophy, but the significance of this is not known. Probably these rapid deaths did not have an immunological basis; further, there was no atrophy of lymph nodes or parabronchial lymphoid tissues. Acute renal failure has been reported (Oreopoulos et al., 1968) in human paraquat poisoning, but we did not record urinary output, serum electrolytes or haematocrit.

This work was supported by USPHS grants GM-01784 and ES-00264.

\section{References}

Almog, C., and Tal, E. (1967). Death from paraquat after subcutaneous injection. Brit. med. J., 3, 721 .

Bullivant, C. M. (1966). Accidental poisoning by paraquat: report of two cases in man. Brit. med. J., 1, 1272-1273.

Campbell, S. (1968). Death from paraquat in a child. Lancet, 1, 144.

Clark, D. G., McElligott, T. F., and Hurst, E. W. (1966). The toxicity of paraquat. Brit. J. industr. Med., 23, 126-132.

Daniel, J. W., and Gage, J. C. (1966). Absorption and excretion of diquat and paraquat in rats. Brit. J. industr. Med., 23, 133-136.

Fennelly, J. J., Gallagher, J. T., and Carroll, R. J. (1968). Paraquat poisoning in a pregnant woman. Brit. med. J., 3, 722-723.

Fisher, H. K., and Clements, J. A. (1969). Effects of the herbicide Paraquat on mechanical properties of rat lungs. Fed. Proc., 28, 526.

Kerr, F., Patel, A. R., Scott, P. D. R., and Tompsett, S. L. (1968). Paraquat poisoning treated by forced diuresis. Brit. med. J., 3, 290-291.

Manktelow, B. W. (1968). The loss of pulmonary surfactant in paraquat poisoning: a model for the study of the respiratory distress syndrome. Brit. J. exp. Path., 48, 366-369.

Matthew, H., Logan, A., Woodruff, M. F. A., and Heard, B. (1968). Paraquat poisoning-lung transplantation. Brit. med. J., 3, 759-763.

Oreopoulos, D. G., Soyannwo, M. A. O., Sinniah, R., Fenton, S. S. A., McGeown, M. G., and Bruce, J. H. (1968). Acute renal failure in case of paraquat poisoning. Brit. med. J., 1, 749-750.

Received for publication April 20, 1970. 